\title{
Reverberações do luto ou acerca da morte em família
}

Adriana Kanzepolsky

Universidade de São Paulo

"a vida é uma festa que desmente suas bodas"

T. K., Solos y solas

003 - "O que é um pai?", pergunta-se como um refrão / ladainha "Kaddish" o poema central de $O$ gueto, livro no qual Tamara Kamenszain constrói um luto pela morte do pai e que escreve em sua memória; um livro em que, mesmo antes do texto, o sujeito lírico se instala no sobrenome paterno ${ }^{1}$. O verso inicial de cada uma das sete estrofes, uma para cada dia em que o luto se confunde com a reza, repete a pergunta de forma idêntica. As sete estrofes, de domingo a sábado, inauguram um dia a mais de orfandade e velam o sonho da órfã em um idioma que, sem o pai, lhe ressoa estrangeiro ${ }^{2}$. Dez homens, que não são o pai, rezam de domingo a sábado e não só não liberam a órfã, como também, com o fim dos sete dias, quando a reza é concluída, a pergunta insiste e continua sem resposta. A pergunta, então, como um

${ }^{1}$ Em memória de Tobías Kamenszain. Em teu sobrenome instalo o meu gueto, reza a epígrafe.

${ }^{2}$ A terceira estrofe diz: "O que é um pai? / Dez homens o invocam na terça-feira / num espaço sem ele / seu idioma / soa estrangeiro". KAMENSZAIN, 2012, p. 43 - Tradução de Paloma Vidal e Carlito Azevedo. 
golpe, retorna ou, para ser mais precisa, o golpe da pergunta é reiterado. Lemos: "O que é um pai? / Com a primeira estrela / chega o shabbat / e ainda não tenho resposta."

O poema parece dizer que não há reza "que jejue vontade de saber" ${ }^{\prime \prime}$ ou que não há reza do outro que sacie a vontade de saber, ou ainda que na boca dos outros a morte do pai pode ser um romance, talvez o romance da morte judia, um romance que, em todo caso, não oferece respostas ${ }^{5}$. Se a pergunta não encontra resposta no aramaico da reza, também não encontrará na boca dos outros homens, acredito, ao invés disso, que a insistência reiterada de seu golpe desperta o sujeito lírico, essa que, como dissemos, se posiciona como filha antes do próprio texto. Alguém que na última estrofe, no mesmo gesto, se inscreve na genealogia paterna e se dispõe a continuar buscando, já não na tentativa de saber, mas para depois, em algum tempo que não se sabe quando, alcançar o esquecido ou concluir o luto, seu luto. Um luto que, embora se afirme no nome do pai com letras judias, se faz por fora dos termos do judaísmo porque, como lemos, "Eles se dispersaram mas eu / filha de Tuvia ben Biniamin / continuarei buscando acordada / para depois / poder esquecer". ${ }^{6}$

${ }^{3}$ KAMENSZAIN, 2012, p. 45.
${ }^{4}$ Tomo a expressão de “Árvore da Vida", outro poema de O gueto. Diz
o verso "não há rabino que jejue vontade de saber.". KAMENSZAIN,
2012, p. 55.
${ }^{5}$ A advertência de converter a morte do outro em literatura, da que
aqui pareceria ser vítima o sujeito lírico, reaparece na boca do pai
em um dos poemas de La novela de la poesía. Diante da sugestão do
sujeito lírico - a filha - que olha a morte de frente, o pai, a caminho
do hospital, responde: "es demasiado literario/ a nadie le sirve
mirar a la muerte/ a esa novela que la escriba notros" (2012,p.377).
${ }^{6}$ KAMENSZAIN, 2012, p.45.O desejo do esquecimento se explicita
em "Dia do perdão": "O que pedimos? / Não que ele volte. / E sim 
2010 - “Do primeiro ao último, se estabelecem entre os livros de poesia enlaces compositivos" ${ }^{\prime \prime}$, afirma acertadamente Enrique Foffani no prólogo de La novela de la poesía. Poesia reunida, de Tamara Kameszain, para se deter em seguida na estrita continuidade que se apresenta entre $O$ eco da minha mãe, de 2010, e La novela de la poesía, de $2012^{8}$. Uma continuidade fundamentada na articulação de ambos os livros sobre a pergunta acerca da morte, indagação que no último se amplia à "família de poetas amigos".

Sem dúvida a observação de Foffani é pertinente para pensar uma série extensa de poemas que desde o primeiro livro têm em seu centro a família - biológica e poética9-e

que nos deixe tranquilas / arrasadas em sua lembrança ansiolítica / resistindo contra seu destino / de pai e marido ido." KAMENSZAIN, 2012, p.49.

${ }^{7}$ FOFFANI, 2012, p.9.

${ }^{8}$ A novela da poesia remete tanto ao título de sua poesia reunida como ao seu último livro.

${ }^{9}$ Já faz mais de uma década que Jorge Panesi escreveu a propósito da publicação de Histórias de amor (e outros ensaios sobre poesia) - livro que compila os livros de ensaios que Kamenszain tinha publicado até o momento - que esta poeta crítica julgava "inventar famílias poéticas", descobrir "parentescos inesperados", e falava também de certa paixão genealógica que regeria seu impulso crítico. Trata-se de um livro em que os capítulos associam o nome de um poeta a uma condição civil - solteiros, viúvos, casados, divorciados - estado ou condição que nomeia a singularidade de seu vínculo com uma tradição poética ou com a matéria da escrita. À leitura de Panesi, que continua sendo precisa, caberia acrescentar agora que, nos últimos livros, este impulso de inventar famílias poéticas, como o descreve, transborda no espaço do ensaio e, desde O eco da minha mãe, "contamina" a lógica de seus livros de poesia. Num primeiro movimento de tentativa, no livro de 2010, em que elege quatro escritoras que já passaram pela experiência da perda e da doença de um ente querido, para que a 
que também retomam núcleos de sentido e conceitos que podemos considerar imprescindíveis, entre os quais o termo gueto que ocupa um lugar central ${ }^{10}$. Agora, se nos detivermos especificamente nos últimos quatro livros (refiro-me a $O$ gueto, Solos y solas, O eco da minha mãe e La novela de la poesía), legível como quatro escansões que, com variantes, constroem um relato de luto, de lutos diversos e que, às vezes, se superpõem e desenham um movimento de dobras e redobras de um livro ao outro, a relação que se concebe é de índole diversa. Não só os três primeiros repetem uma estrutura idêntica, já que estão divididos em três seções, sendo que a terceira é constituída por um extenso poema que recupera e sintetiza as seções anteriores ${ }^{11}$, mesmo que alguns poemas, em particular, tomados em seu "isolamento e salvação", estejam estreitamente vinculados; por um lado, a partir de certa recuperação de procedimentos ou de procedimentos que ressoam entre um poema e outro e, num sentido diverso, porque é possível ler alguns deles como uma réplica ou uma resposta às perguntas abertas nos poemas dos livros precedentes. Um movimento que pode se seguir com especial clareza entre O gueto e La novela de la poesía, livro que retoma e explicita perguntas formuladas no livro de 2003.

ajudem a falar sobre a doença e a perda da mãe, e como o impulso constitutivo de A novela da poesia, de 2012, em que o que estrutura o livro é a "família de amigos poetas mortos", que aparecem nas mais diversas posições.

${ }^{10}$ Aprofundei estas reflexões em "As línguas do luto", prólogo do livro O gueto (trad. Carlito Azevedo e Paloma Vidal), e O eco de minha mãe (trad. Paloma Vidal),de Tamara Kamenszain, Rio de Janeiro, 7 Letras, 2012.

${ }^{11}$ Em A novela da poesia se repete a divisão em três seções, mas muda a extensão dos poemas das duas primeiras partes, em que não fica muito clara a separação entre um poema e outro. Por outro lado, a última seção não pode ser lida como uma síntese dos "motivos" das seções anteriores. 
Por sua vez, O eco da minha mãe se abre com uma epígrafe citada no primeiro verso de Los heraldos negros, de César Vallejo: "Há golpes na vida tão fortes... eu não sei". A continuação do poema que inicia o livro recupera a citação, lê o verso com insistência, e na apropriação distancia os hemistíquios, muda de lugar as reticências para, no verso que instala desde o começo a repetição como procedimento nodal deste livro,dizer em eco com a mãe: "eu não sei... eu não sei... eu não sei"12.

Cito o poema em sua totalidade: "Há golpes na vida tão fortes / que me demoro / no verso de Vallejo / para deixar dito de saída / o que sem dúvida o eco da minha mãe / rematará entre reticências: / eu não sei... eu não sei... eu não sei.".

Assinalei antes que $O$ gueto constrói um luto pela morte do pai e detém um efeito de martelo produzido pela pergunta / refrão “O que é um pai?". Já O eco da minha mãe avança nas figuras do luto ${ }^{13}$ e deixa o pai em segundo plano para se deter na dor pela doença e pela morte da mãe numa série de poemas organizados sobre a retórica da repetição, a da doença que acomete esta mulher. Todavia, considero que ambos os livros estabelecem uma relação de espelho (ou justamente de eco?), no qual a pergunta que martela e abre os versos de "Kaddish" se volta para escutar aqui, no golpe da repetição que funda a lógica dos poemas. E se atentarmos ao poema que acabei de citar, vemos que não só o golpe se diz no procedimento, mas na citação de Vallejo o poema o explicita como golpe. Golpeia a dor, golpeia a repetição, e a citação "distorcida" do verso de

${ }^{12}$ KAMENSZAIN, 2012, p.75.

${ }^{13}$ Em tal sentido, o poema que abre La novela de la poesía sintetiza: "¿Ya hablé de la muerte?/ Murió mi hermano/ murieron mis padres/ murió el padre de mis hijos/ tantos amigos murieron/ y dije y digo que no están más./ ¿Eso es hablar de la muerte?/ Dejé anotado que se fueron/ les dediquélibros los nombré/ por sus nombres me anoticié/ de que nadieme contestaba/ ¿Eso es hablar de la muerte?". KAMENSZAIN, 2012, p. 373. 
Vallejo afirma como um não saber reiterado, eu não sei, eu não sei, aquilo que em "Kaddish" o poema nomeava como a espera de uma resposta que não chega durante os sete dias de duração da reza.

Em La boca del testimonio, ao se referir a esses versos de Vallejo, Kamenszain sustenta que "no entre - entre as reticências ${ }^{14}$ - aparece, como uma flor isolada, a suspensão do sentido." ${ }^{15}$. Quando seu poema deixa o "eu não sei..." na boca da mãe e o repete, a suspensão do sentido que lê no verso de Vallejo se torna um sem-sentido extremo: o sem-sentido do golpe e o sem-sentido da doença, da fala sem-sentido da mãe porque a repete sem memória.

O final do poema insiste no golpe e o reitera com um verbo que instaura um paradoxo, quase um oxímoro. Lemos: "o que sem dúvida o eco da minha mãe / rematará entre reticências: / eu não sei... eu não sei... eu não sei." (itálico meu). As várias acepções do verbo rematar implicam sempre na ideia de um final, de algo que se acaba, seja através de uma morte - e é a primeira acepção -, seja na graça de uma piada ou no futebol, quando se culmina uma jogada. Aqui, todavia, o verbo rematar não é unicamente uma promessa para o futuro, mas aquele que rematar fará isso em eco, algo que sabemos termina em um desfalecimento paulatino do som até, cada vez mais, alcançar o sem-sentido total.

Kamenszain escreve em La boca del testimonio que "pedir ao outro que diga algo é o modo que a poesia tem de manter viva a possibilidade de dizer" ${ }^{16}$. Uma proposição que poucas linhas abaixo se completa com a seguinte afirmação: "Porque a testemunha já não é quem sabe mais que os outros, mas quem precisa dos outros para saber mais de si." ${ }^{17}$.

${ }^{14}$ Em espanhol, as reticências são "puntos suspensivos" (NT).

${ }^{15}$ KAMENSZAIN, 2007, p.18.

${ }^{16}$ KAMENSZAIN, 2007, p.11.

${ }^{17}$ KAMENSZAIN, 2007, p.11. 
Caberia perguntar, então, se esse "eu não sei" da citação de Vallejo, que organiza o poema inaugural de O eco da minha mãe, além de falar sobre o lamento, também não leva ao convite ou a um pedido para que o outro, algum outro, responda a essa pergunta encerrada na afirmação do não saber.

Por outro lado, se o cruzamento entre esse poema e o ensaio La boca del testimonio abre essa interpretação, a leitura do poema que fecha La novela de la poesía transforma numa certeza aquilo que aqui está só sugerido. Explico-me: com diversos graus de intensidade e de forma velada, em O gueto, Solos y solas e $O e c o . .$. se escuta uma pergunta acerca da possibilidade que a poesia tem de falar da morte. La novela de la poesía, um livro que me atrevo a dizer que fecha um ciclo, torna explícita essa pergunta em um verso que se repete várias vezes pelo livro: "Isso é falar da morte?". Trata-se de uma pergunta que pontua obsessivamente o primeiro poema, ditando sua cadência, e reaparecendo de maneira pontual nos poemas que se seguem. As respostas são tentativas; vagueiam soluções diversas e previsivelmente não chegam a nenhuma resposta satisfatória, nem certeira. Por que, então, trazê-la para o assunto agora? Porque nos dois últimos versos do poema final lemos: "Isso é falar da morte? / Você saberá...", dois versos nos quais com alguma transparência é possível ler um tipo de continuação ou de tradução do "eu não sei" que abre O eco da minha mãe, sobretudo, porque os dois versos podem ser lidos como um convite quase explícito para que o outro responda.

Estamos novamente diante de alguém que, na pergunta, afirma não saber e situa o outro como um interlocutor, alguém que, talvez, tenha alguma resposta ou alguma opinião. Um movimento que não fala exclusivamente do luto e da morte, mas que repete no registro do poema aquela afirmação que citávamos antes, que assegura que "pedir ao outro que diga algo é o modo que a poesia tem de manter viva a possibilidade 
de dizer"18, em que fica claro que só vai poder dizer - escrever - caso se afirme seu não saber.

2012 - A propósito da publicação de La edad de la poesia, em 1996, um livro de ensaios que quatro anos depois Tamara Kamenszain compilará junto com outros em Historias de amor (Y otros ensayos sobre poesia), Jorge Panesi escreve: "A poesia está obrigada a narrar porque seu outro ou sua outra (o romance da poesia) lhe impõe a liberdade de ser quem é" ${ }^{19}$. Dezesseis anos depois, aparece a poesia reunida de Tamara Kamenszain, cujo título, La novela de la poesía, reúne todos os livros de poemas publicados até o momento e um inédito. Trata-se de um livro que desde o título remete a duas linhas de força que o articulam: seu vínculo com o narrativo (a novela de que Panesi falava muitos anos atrás, mas também o ensaio) e o diálogo que seus poemas instauram com a palavra de outros poetas e com a de algum narrador, como Mario Levrero. Escritores, todos, que compartilham a condição de estarem mortos e muitos deles a de terem sido amigos de Kamenszain.

O movimento do livro se dá em duas direções distintas, mas que se interseccionam fortemente: a volta a certa zona da produção de poetas como Néstor Perlongher, Héctor Viel Temperley, Alejandra Pizarnik, César Vallejo e Osvaldo Lamborghini, todos citados por Kamenszain para ajudá-la a falar sobre a morte - essa pergunta que mais uma vez a fustiga e diante da qual ela ensaia tentativas de respostas que são sempre insuficientes - e concomitantemente com eles ela arma mais uma vez no e com o registro poético, ou com um registro poético que ensaia, o romance familiar da poesia que vinha escrevendo em seus textos ensaísticos desde meados da década de oitenta ${ }^{20}$. Neste último livro, volta o desenho de

${ }^{18}$ KAMENSZAIN, 2007, p.11.

${ }^{19}$ PANESI, 1998, edição online.

${ }^{20}$ Acerca da recuperação desse romance através dos poemas, Enrique 
uma família de escritores onde são citados muitos nomes que foram objeto de seus escritos críticos desde La edad de la poesía, de 1996, até La boca del testimonio, de 2007: os já mencionados, mas também Celan, Levrero, Gambarotta, Amelia Biagioini e Héctor Libertella, referido como o pai de seus filhos ${ }^{21}$. Escritores sobre os quais os poemas desdobram, por um lado, uma leitura pontual que põe em cena ou indaga o saber desses poetas / esses poemas sobre a morte, sobre o saber falar da morte e, junto com isso, o livro constrói um tipo de arquivo das formas poéticas da literatura argentina nas últimas décadas. É assim que no começo de um dos poemas escreve: "La prosa poética ya fue/la novela lírica con evocaciones de infancia/ ya fue ya fue ya fue/la poesía que se las da de narrativa/ también ya fue salvo cuando cuenta"22, versos que sintetizam isso que nomeei como arquivo e aos que poderiam pensar como um inventário de bens na construção de um luto ou de uma herança de um sujeito lírico que no último poema afirma: "hay corte de verso pero también hay/ un verso que se encabalga con otro/ si van de la mano ¿cuentan algo?/ no sé pero te aseguro/que con toda el alma quieren seguir contando"23.

Nesse sentido, então, o livro se desfaz entre o que tem ("uma épica do que não / tem" ${ }^{24}$ ) e o que "já foi", para deixar aberta a expectativa ou, talvez, inclusive, a possibilidade da narração. Um

Foffani assinala: “Agora, 'o romance da poesia' aponta para o revelar da capacidade da poesia para escrever sua própria novela por outro meio. O outro meio é paradoxalmente escrevê-la através da poesia, sem narrá-la, não apelando para a narrativa." FOFFANI, 2012, p.7.

${ }^{21} \mathrm{O}$ poema começa dizendo: "El padre de mis hijos/ fue un hombre de palabra/ moribundo les decía a las enfermeras/ cuando le preguntaban cómo se sentía/ acá estoy en la dulce espera". KAMENSZAIN 2012, p.378.

${ }^{22}$ KAMENSZAIN, 2012, p.385.

${ }^{23}$ KAMENSZAIN, 2012, p.393.

${ }^{24}$ KAMENSZAIN, 2012, p.384. 
modo de dizer que os poemas do livro anterior tinham afirmado com a mesma certeza como desejo, mas também como impossibilidade.

O poema que encerra $\mathrm{O}$ eco da minha mãe assevera: "e uma coisa vai ficando clara: não posso narrar / nunca pude me soltei rápido da mão dela / e entre duas mortes o pretérito agora me sustenta / é uma ponte que não se vê ficou detida / debaixo caminha a narradora que não fui em cima / passam direto as histórias fugindo". ${ }^{25}$ Perder o relato da mãe, concebida como aquela que a elegeu como testemunha, como a que sustenta o sonho em sua qualidade de desejo, tal como aponta em um ensaio recente, ${ }^{26}$ é ter vedada a possibilidade da narração, coisa que $\mathrm{O}$ eco... tem clara e constrói como luto.

${ }^{25}$ KAMENSZAIN, 2012, p.115.Em "Ideia da prosa", texto em que Giorgio Agamben pensa a figura do enjambement como aquela que diferenciaria o verso da prosa e lhe conferiria sua identidade, afirma que a poesia vive da discórdia entre o sentido e o som, quer dizer, entre o elemento métrico e o elemento sintático e é ali onde afirma sua identidade. Todavia, assinala Agamben, no momento dessa quebra o verso é atraído para lançar uma ponte para o verso seguinte, com o objetivo de alcançar aquilo que negou fora de si. Penso que a escolha da palavra "ponte" para descrever a função do enjambement põe luz sobre o poema de Kamenszain. Como se ao falar da impossibilidade da narração, da impossibilidade da prosa, o poema afirmasse que o sujeito lírico não consegue estabelecer uma ponte entre uma história e outra, não acerta o enjambement, uma figura que, por outro lado, é constitutiva de seus poemas. Isso significa que o poema parece lamentar que entre uma história e outra o enjambement não se produz. ${ }^{26}$ Em "Narrar a si mesmo, poetizar o outro. Os casos Molloy Kamenszain", ensaio que indaga as continuidades e especificidades entre a poesia e a prosa, a partir do diálogo que $O$ eco da minha mãe estabelece com Desarticulações, de Sylvia Molloy, "romance" que gira em torno de uma amiga doente de Alzheimer e que, citada e lida, se converte em poema, em $\mathrm{O}$ eco..., Kamenszain escreve: "Tendo a crer que em ambos os casos a testemunha é quem sustenta o sonho, entendido aqui como o desejo de cada uma das escritoras". KAMENSZAIN, texto mimeografado. 
Enquanto La novela de la poesía insiste no desejo de narrar, de que o poema conte e não fuja do relato, como assegura também no mesmo ensaio ${ }^{27}$, pode-se dizer que fundamentalmente o que o livro de poemas realiza é uma extensa cena de leitura ou, mais pontualmente, a imagem de alguém - um sujeito da enunciação - que se põe no lugar de uma leitora. Alguém que lê os textos de outros, mas também, e talvez, sobretudo, seus próprios textos, alguém que lê as operações que vêm realizando desde o livro de 2003 na intenção de pôr em palavras a morte e o luto.

De forma paralela, mas indissociável dessa imagem, o livro constrói o sujeito lírico como alguém que observa e indaga cenas familiares atravessadas pela morte iminente ou que já aconteceu. Nesse sentido, são exemplares os versos iniciais de La novela de la poesía, passíveis de serem lidos como um registro no qual lista e enumera as operações que sua escrita levou a cabo na tarefa de realizar o luto; um exercício de memória e constatação onde o poema que agora escreve se acrescenta como uma dobra a mais ao exercício de repetir a morte do outro para torná-la crível. Lemos:" ¿Ya hablé de la muerte?/ Murió mi hermano/murieron mis padres/ murió el padre de mis hijos/tantos amigos murieron/y dije y digo que no están más. ¿Eso es hablar de la muerte?/ Dejé anotado que se fueron/ les dediqué libros los nombré/

${ }^{27}$ É justamente para descrever a operação que leva a cabo com a frase do texto de Molloy: "ontem descobri que eu tinha me tornado ainda menos para ela" - que aos seus ouvidos soa como um verso -, frase que o poema abre, "narra", e desloca a uma cena de desconhecimento protagonizada pelo sujeito lírico e sua mãe, que Kamenszain escreve: "Quis forçá-lo (forçar o poema) a baixar a terra, como a epígrafe. Impus ao poema não deixar-se ganhar pela tentação de não contar o conto", algo que um pouco mais atrás no mesmo ensaio justifica como uma necessidade de torcer o rumo de sua poesia e deslocá-lo do pódio metafórico. Um movimento, diga-se de passagem, que preside a escrita de La novela de la poesía. KAMENSZAIN, texto mimeografado. 
por sus nombres me anoticié/ de que nadie me contestaba./ ¿Eso es hablar de la muerte?"28

Se a partir de Solos y solas a poesia de Kamenszain tende ao narrativo, em La novela de la poesía o registro que predomina é o de uma conversação que se faz no cruzamento entre a lembrança das imagens da morte em família e a remissão às mínimas cenas de leitura, nas quais o sublinhado de um verso de outro poeta faz andar o próprio poema ou se entrelaça com este. É assim que junto com o sujeito lírico lemos "debajo estoy yo" "debajo estoy yo", o refrão de Alejandra Pizarnik, ou "Nacien una generación/La muerte y la vida estaban/ en un cuaderno a rayas", três versos de Osvaldo Lamborghini fundamentais para a lógica do livro, ou também, um refrão em negrito de Néstor Perlongher: "Ahora que me estoy muriendo" "Ahora que me estoy muriendo". Por sua vez, é o corpo doente e desconhecido de Héctor Viel Temperley o que o poeta busca em dois versos de Hospital Britânico: "voy hacia lo que menos conocíen mi vida:/ voy hacia mi cuerpo". Corpo e palavras que se cruzam também nos versos de Celan ("Rabí/ a este/ circuncídale la palabra"). César Vallejo ("Cadáver lleno de mundo") e Amelia Biagioni ("Si alguien me llamara me buscara/ preguntaría por 'una niña de mil

${ }^{28}$ KAMENSZAIN, 2012, p. 373. Sem dúvidas, poderíamos estabelecer aqui uma relação estreita entre esses versos e as condições que formam a compreensão ou aceitação da morte do outro, segundo explica Derrida em Memórias para Paul de Man. A citação é extensa, mas pela semelhança com o poema, transcrevo-a: “O que em nossa tristeza chamamos a vida de Paul de Man, e responder em e ao nome de Paul de Man. No momento da morte o nome próprio permanece; através dele podemos nomear, chamar, invocar, designar, mas sabemos, podemos pensar [...] que Paul de Man mesmo, o portador desse nome e único polo destes atos, estas referências, nunca voltará a respondêlo, nunca responderá a ele mesmo, nunca mais, exceto através do que misteriosamente chamamos nossa memória". DERRIDA, 1998, p. 60. 
años"). E é uma nova citação de Osvaldo Lamborghini, dessa vez como um epitáfio que escutamos em: "No escribió/poesía/sin/ embargo/latenía//Toda adentro: igual/desdeñoso/impertérrito/NO/ ELEGÍA", para encerrar o livro com Vallejo que declara: "César Vallejo ha muerto".

Por um lado, as citações assinalam uma posição de enunciação: nascer em uma geração, ser uma menina de mil anos e,por outro, são lidas, interrogadas, com o propósito de medilas em sua precisão diante da possibilidade/impossibilidade de aproximar-se de um dizer sobre a morte e compará-las com suas próprias operações no presente do poema e na trajetória de sua escrita sobre o tema.

Caberia perguntar, talvez, onde radica a diferença entre esses poemas que constroem uma leitura reflexiva das citações que enumerei, ou que remetem a uma aula sobre Osvaldo Lamborghini, ou inclusive entre um poema em que a propósito de La novela de la poesía luminosa, de Mario Levrero, Kamenszain lista as perguntas recorrentes e inevitáveis que a crítica literária lhe faz sobre os textos conhecidos como escrituras do eu, e um texto concebido como ensaio? Uma pergunta que inclusive a própria Kamenszain deixa entreaberta a partir do momento em que conta que La novela de la poesía era o título pensado para um livro de ensaios onde pergunta "sobre o que compartilham e sobre o que descartam uma da outra, poesia e narrativa".

Não vou repetir aqui os argumentos do texto de Kamenszain, referidos para a narrativa e não para o ensaio, no qual em grandes traços compartilha com Kate Hamburguer a concepção de que aquilo que define um poema como tal é o que remete infalivelmente ao eu lírico, mesmo que me interesse apontar que nesses poemas, tão próximos do ensaio, aquilo que constrói sua especificidade é a recorrência obsessiva da pergunta acerca da possibilidade que tem o poema de falar da morte. Quero dizer, seu poema, não só o poema que está escrevendo ou que escreveu, mas também qualquer poema. 
A pergunta "Isso é falar da morte?" que - como disse atua como um refrão que martela e que pela sua insistência se aproxima da contundência transparente que Kamenszain vê no "ahora que me estoy muriendo", o refrão que Perlongher, curado do barroco, escreveu en "Alabanza y exaltación del Padre Mario", é o ponto de cruzamento entre a rememoração das mortes familiares e a leitura ou as leituras dos poetas que escreveram sobre a morte, à beira da morte. É o refrão o que permite reconhecer que ali há um poema e é no refrão que se concentra e condensa o sentido do livro.

O refrão e o corte do verso porque, como afirma: "ningún modo seco o moderno/ o veraz o realista/ puede hacer le decir sin cortes/ algo a la poesía" 29. Já observou Enrique Foffani que "o corte é [...] um dostemas mais cruciais dessa poética" e especifica "do corte do verso ao corte da vida na morte." ${ }^{30}$. Outra vez a observação de Foffani é precisa; um percurso pelo corpus que escolhemos evidencia esse tema em títulos, epígrafes, versos, etc., mas diria que nesse poema em particular a referência ou a recorrência ao corte se apresenta indistintamente como um tipo de procedimento indispensável para o poema tanto na forma - quero dizer, não para seus poemas em particular, mas para os poemas em geral -, mas também que, quando nessa ocasião escreve que a poesia não pode se dizer sem corte, afirma que a poesia só pode se dizer com o que falta.

(Tradução de Mariane Tavares)

\footnotetext{
${ }^{29}$ Perguntando-se pela inscrição do sujeito no poema de Cucurto, que consiste só numa lista de nomes femininos, Kamenszain conjectura que possivelmente o sujeito se encontra no corte do verso. (2012, p.379).

Cf: "Narrar a si mesmo, versificar o outro: os casos Molloy Kamenszain".

${ }^{30}$ FOFFANI, 2012, p.13.
} 


\section{Referências bibliográficas}

AGAMBEN, Giorgio. Ideia de prosa. Lisboa: Cotovia, 1999.

DERRIDA, Jacques. Memorias para Paul de Man. Barcelona: Gedisa, 1998.

FOFFANI, Enrique. “Tamara Kamenszain: la poesía como novela luminosa". In KAMENSZAIN, Tamara. La novela de la poesía. Buenos Aires: Adriana Hidalgo editora, 2012.

casos Molloy Kamenszain" (mimeo).

"Narrarse a si mismo, poetizar al otro. Los

KAMENSZAIN, Tamara. El eco de mi madre. Buenos Aires: Bajo la luna, 2010.

KAMENSZAIN, Tamara. El ghetto. Buenos Aires: Sudamericana, 2003.

KAMENSZAIN, Tamara. Historias de amor (Y otros ensayos sobre poesía). Buenos Aires: Paidós, 2000.

KAMENSZAIN, Tamara. La boca del testimonio. Lo que dice la poesía. Buenos Aires: Norma, 2007.

KAMENSZAIN, Tamara. La novela de la poesía. Buenos Aires: Adriana Hidalgo editora, 2012.

KAMENSZAIN, Tamara. Solos y solas. Buenos Aires: Lumen, 2005.

KAMENSZAIN, Tamara. "As línguas do luto". In KAMENSZAIN, Tamara. O gueto (trad. Carlito Azevedo e Paloma Vidal), O eco da minha mãe (trad. Paloma Vidal). Rio de Janeiro: 7 Letras, 2012.

PANESI, Jorge. "Piedra libre: la crítica terminal de Tamara Kamenszain". Zunino \& Zungri, www.beatrizviterbo.com.ar. 


\section{Resumo}

A partir da leitura de "Kaddish", poema central de O gueto (2003), de Tamara Kamenszain, cujo refrão se pergunta insistentemente "O que é um pai?", o presente trabalho lê a persistência dessa figura e as diversas modulações literais e metafóricas - que a mesma adquire em $O$ eco da minha mãe (2010) e La novela de la poesia (2012), livros em que, também, o sujeito lírico constrói um luto e indaga sobre a possibilidade que a poesia tem de falar sobre a morte. Lemos, pontualmente, como a construção do luto reverbera entre um livro e outro.

\section{Resumen}

A partir de la lectura de "Kaddish", poema central de El ghetto (2003) de Tamara Kamenszain, cuyo estribillo se pregunta insistentemente "¿Qué es un padre?", el presente trabajo leer la persistencia de esta figura y las diversas modulaciones -literales y metafóricas- que la misma adquiere en El eco de mi madre (2010) y La novela de lapoesía (2012), poemario sen los que también el sujeto lírico construye un luto e indaga acerca de la posibilidad que tiene lapoesía de decir la muerte. Leemos, puntualmente, cómo la construcción del luto reverbera entre un libro y otro. 